\title{
Analysis of precipitation for the past 20th century and its multi-decadal oscillation: a case study of Bankura Town, Bankura, West Bengal
}

\author{
Sadhan Malik ${ }^{1} \cdot$ Baisakhi Das $^{1} \cdot$ Biswajit Das $^{1} \cdot$ Subodh Chandra Pal $^{1}$
}

Received: 4 November 2016 / Accepted: 24 November 2016 / Published online: 30 November 2016

(C) Springer International Publishing Switzerland 2016

\begin{abstract}
The present investigation is based on maximum monthly precipitation for the past 20th century of Bankura Town, of West Bengal. The analysis was based on 100 years time series of maximum monthly rainfall data of Bankura Town. First of all, data sets were analysed as a whole and in a separated part of it using Linear Regression model. We have found that there were no such good relationships or trends do exist at all. But using 30 years of moving average, we have found oscillatory trends within this data, which seems to be very much effective in understanding and dealing with precipitation trends. This study concluded that precipitation trends oscillatory must be used for analyse of the past.
\end{abstract}

Keywords Maximum monthly precipitation - Multidecadal oscillation $\cdot$ Moving average $\cdot$ Bankura Town

\section{Introduction}

Nature of the regional and local-scale precipitation is an extremely important for the judgment of hydrological consequences, such as flooding and droughts in the

Sadhan Malik

sadhanmalik06@gmail.com

Baisakhi Das

baisakhidasgeo93@gmail.com

Biswajit Das

biswajitdas1119@gmail.com

Subodh Chandra Pal

geo.subodh@gmail.com

1 Department of Geography, The University of Burdwan, Burdwan 713104, West Bengal, India context of climate change (Huang et al. 2015), risk of hunger, global and regional pattern of water resources, irrigation, ecological challenges, conflict related to water resources, groundwater reserves and its quality, water pollution (particularly river water pollution and its impact over the river basin managements). Precipitation is considered as a fundamental part of the hydrologic cycle and any kinds of changes in it straightforwardly influence the water resources of concerned areas (Chahine 1992). In case of country like India, this becoming significantly important for its food security and economy, for being still dependent on the timely availability as well as the quality of monsoon (Kumar et al. 2010). Various attempts have been made in to verify trends in the rainfall at national and regional scales but most of the rainfall studies were restricted to the analysis of annual and seasonal variations with respect to its overall assessment based on linear trends. Based on the different range and quality of data they have identified different kinds of trends. Increasing trends were identified by several scholars like Kumar et al. (2010), Singh et al. (2016) and so on. Sinha Ray and Srivastava (1999), Mirza et al. (1998), Vennila (2007) shows a decreasing trend. This kind of variations may be due to the fact of spatial as well as temporal. As most of their work was based on linear trends of precipitation, result it seems to be in ambiguous. Several scholars like Faure and Gac (1981), Folland et al. (1984); Schlesinger and Ramankutty (1994), Fischer and Mieding (2005), Kerr (2000), Delworth and Mann (2000) and Willems (2013) found multi-decadal oscillatory behavior instead of linear behavior. In case of India such kinds of study are very rare as well as maximum monthly precipitation have not been studied yet. In this study, we have taken the precipitation of 20th century (1st January, 1901-31st 
December, 2000) precipitation data of Bankura Town station (Lat-23.23 and longitude-87.08) for trend analysis. It is located in Bankura district of West Bengal under monsoon climatic condition. The main focus of this study is to assess the trends and multi-decadal oscillations of maximum monthly rainfall for the past 20th century of Bankura Town.

\section{Data base and methodology}

Trend analysis has proved to be a useful tool by providing useful information on the possibility of changes in the future (Yue and Hashino 2003). In this study we have got a unique opportunity to study the monthly rainfall data of Bankura Station (Fig. 1) for a period of past

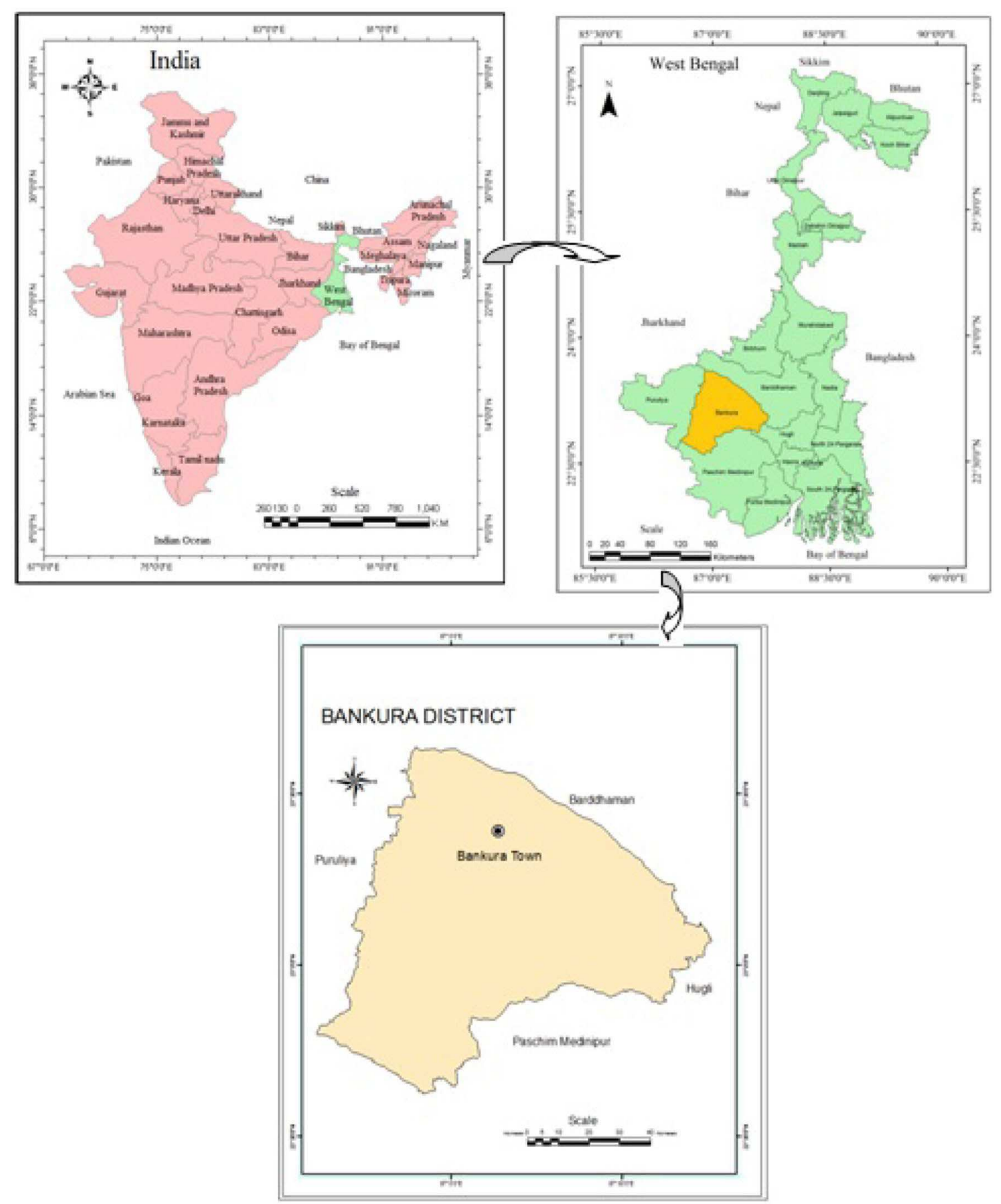

Fig. 1 Location map of the study area 
20th century (1901-2000). Data were obtained from the Indian water portal (website: http://www.indiawaterportal.org/met_data/) (Gajbhiye et al. 2016). First of all we have extracted the maximum precipitation month for each an individual year. Then we have used 30 years of average moving window for getting stable maximum monthly precipitation amount out this data set. As it is generally said considered that 30 years of weather statistics represent climate of any area that's why we have used 30 years of average. After that analysis of extreme anomalies were done based on the Willems (2012). In this way we have crave out the trends and its multi-decadal oscillation behavior of the study area.

Table 1 General statistical characteristics maximum monthly rainfall of Bankura

\begin{tabular}{lc}
\hline Statistical properties & $1901-2015$ \\
\hline Range & 479.50 \\
Minimum & 199.5 \\
Maximum & 679.00 \\
Standard error & 8.54 \\
Mean & 394.27 \\
Median & 382.23 \\
Mode & 396.26 \\
Standard deviation & 91.61 \\
\hline
\end{tabular}

Source: Calculated by authors

\section{Result and discussion}

\section{General statistical characteristics of maximum monthly rainfall for Bankura}

Basic statistical attributes of monthly maximum precipitation events for the period of 100 years (1901-2000) of Bankura Station was analysed, such as range, minimum, maximum, mean, standard deviation (SD), standard error, median, mode and coefficient of variation (Table 1; Fig. 2). Here we have found mean value of $394.27 \mathrm{~mm}$ per month. Here high and low maximum precipitation for Bankura Town is 199.5 and $679 \mathrm{~mm}$ respectively. So, range monthly maximum precipitation is very high for this region. Standard deviation for the past 20th century was very high (91.61). So, this data set is very much discrete in nature. As the study area belongings from monsoon region, that's why most of the rainfall was occurred during monsoon seasons. Precipitation for rest of the months remains low.

\section{Multi-decadal oscillation trend of Bankura Town}

Figure 3 showing linear trends of monthly maximum precipitation (MMP), which is not showing any significant trends and pattern. Here we have found ' $b$ ' value of only about 0.08 . Where the $p$ value is more than 0.5 as well as explained variance is very close to 0 . So, linear trends for this area may not be successful (Fig. 3).

Now we have applied the 30 years of moving average window to understand the MMP trends of Bankura Town.

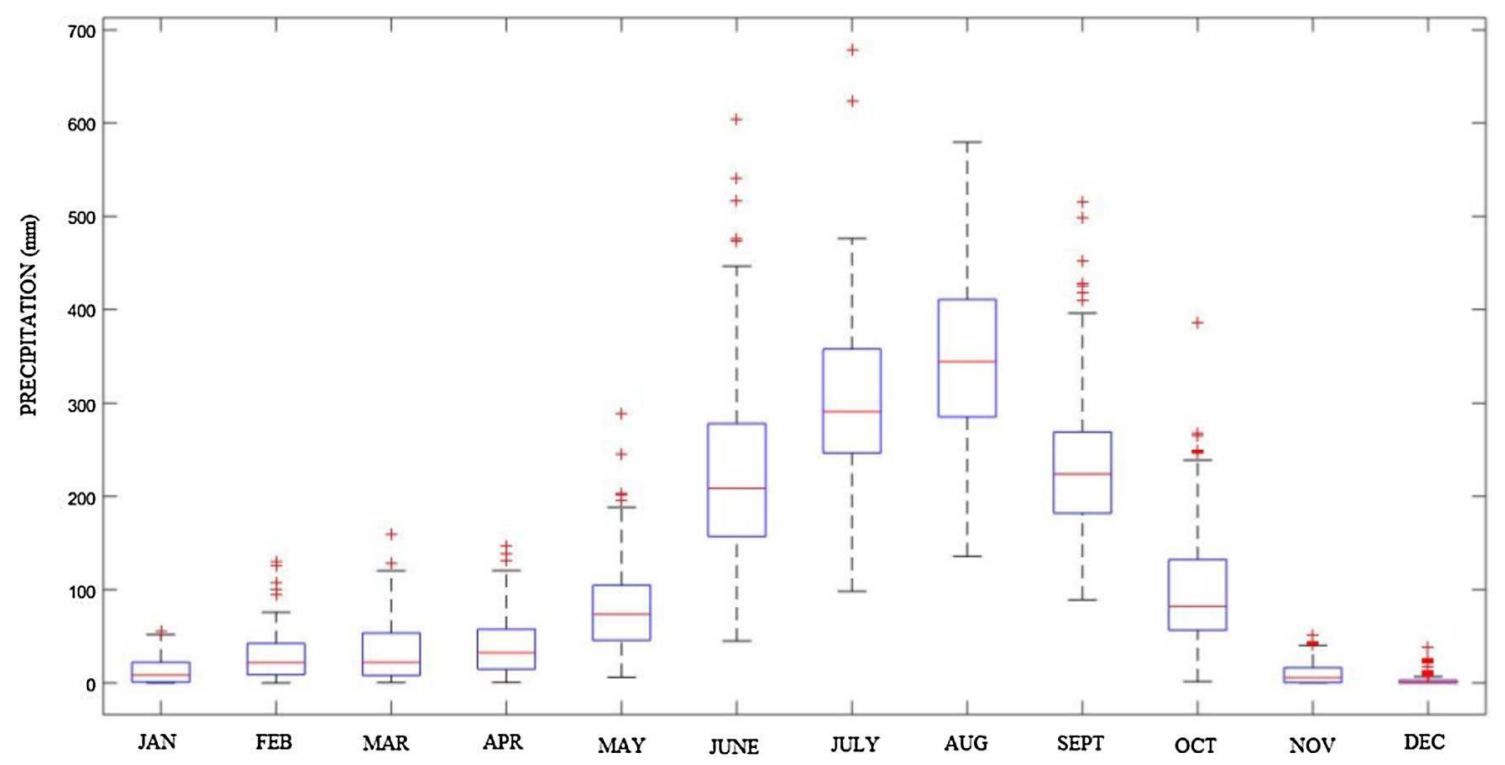

Fig. 2 Distribution of monthly precipitation of Bankura Town for the last 20th century 
Fig. 3 General trends for maximum monthly precipitation
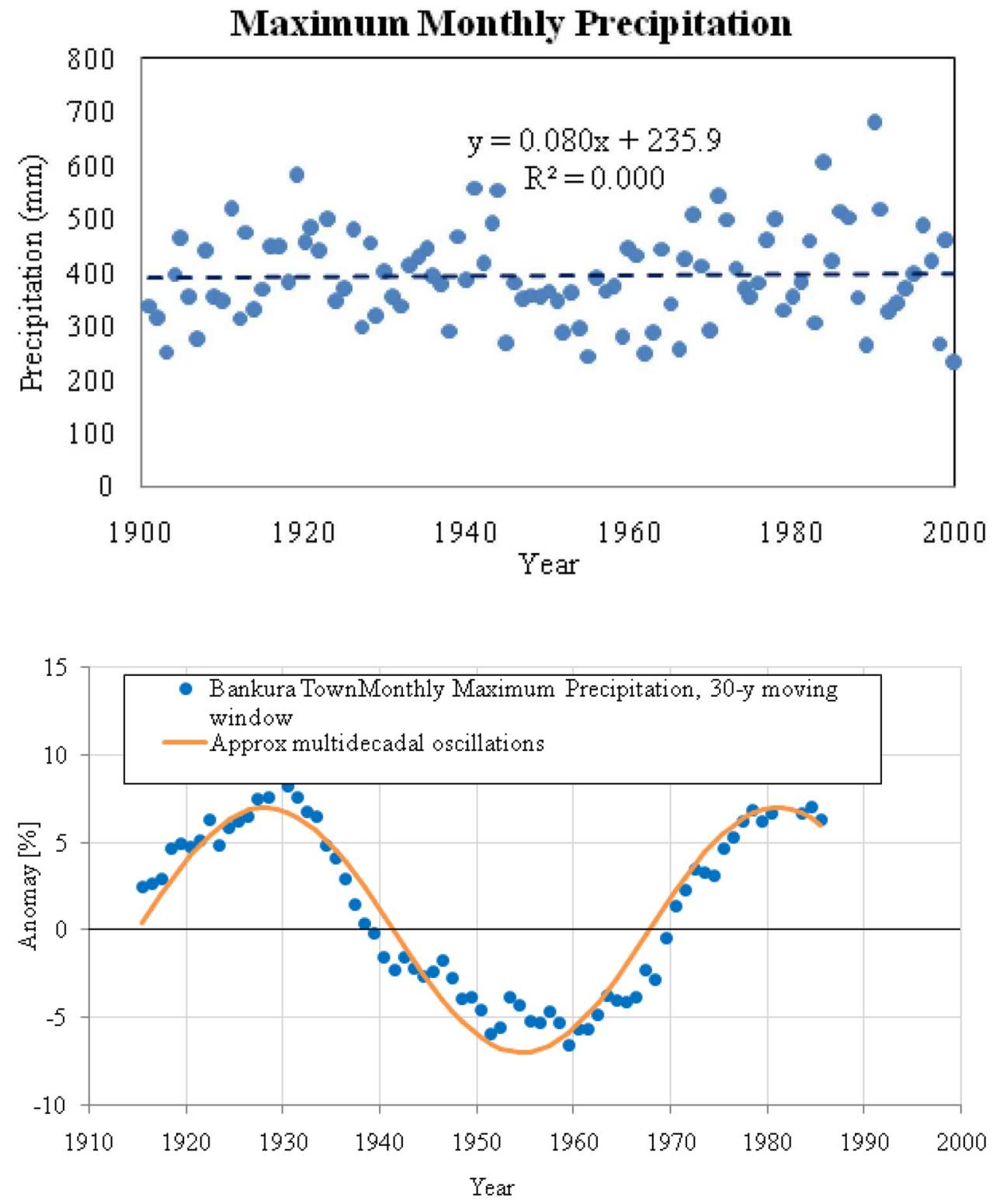

Fig. 4 Cyclic to quasi-cyclic oscillation with periods of 30 years of moving average window length for maximum monthly precipitation
From the Fig. 4, we have found some sort of cyclic to quasi-cyclic oscillatory trends around its grand average of MMP (394.27 mm) for the past 20th century (Fig. 4).

From this Fig. 4, we have also identified two types of trends based on 30 years average MMP value, such as oscillation high and low. Trends were considered as Oscillation high when it was above the grand mean and below it was considered as oscillation low (Table 2). We have also found alternating positive and negative trends in MMP. Along with that oscillation high and successive low periods were identified such as 1915-1937, 1938-1970 and 1971-2000 (mid-value for 30 years average) representing alternating high and low oscillation periods respectively (Fig. 4).
Table 2 Oscillation high and low for the past 20th century of Bankura Town

\begin{tabular}{ll}
\hline Range of middle class year & Nature of oscillation \\
\hline $1915-1937$ & High \\
$1938-1970$ & Low \\
1971 onwards & High \\
& Few more years may remain in high \\
& after low oscillation is expected \\
\hline
\end{tabular}

Source: Author's calculation 


\section{Conclusion}

Precipitation events are natural phenomena. Natural systematic variability is attached with these kinds of event. MMP of Bankura also showing oscillatory nature. Here linear trends will not be enough for the MMP study. Because of linear trends indicates overall assessment and its degree of slope based on entire observation, that's why we have found a low amount of variance explained (0.002) as it has ignored the natural variability. Although linear regression is able to detect the change throughout the observation of MMP, but it fails to enlighten the future trends. We have found that oscillations provide better knowledge of understanding on the past behavior of MMP. So, in understanding the nature of precipitation, oscillatory behavior of MMP is far more important than the overall trend. As we know that the past and present are the keys to the future, so, this oscillatory behavior will also help us to understand the challenges before mankind as well help in taking some sustainable solutions to take. So, this kind of study is essential for diverse discipline as well as for planning purpose for any country.

\section{References}

Chahine MT (1992) The hydrological cycle and its influence on climate. Nature 359(6394):373-380

Delworth TL, Mann ME (2000) Observed and simulated multidecadal variability in the northern hemisphere. Clim Dyn 16(9):661-676

Faure H, Gac JY (1981) Will the Sahelian drought end in 1985? In at Rossignol-Strick M (1985) Mediterranean quaternary sapropels, an immediate response of the African monsoon to variation of insolation. Palaeogeogr palaeoclimatol palaeoecol 49(3):237-263

Fischer H, Mieding B (2005) A 1000-year ice core record of interannual to multidecadal variations in atmospheric circulation over the North Atlantic. Clim Dyn 25(1):65-74

Folland CK, Parker DE, Kates FE (1984) Worldwide marine temperature fluctuations 1856-1981. Nature 310:670-673

Gajbhiye S, Meshram C, Singh SK, Srivastava PK, Islam T (2016) Precipitation trend analysis of Sindh River basin, India, from 102-year record (1901-2002). Atmos Sci Lett 17(1):71-77

Huang J, Liu F, Xue Y, Sun S (2015) The spatial and temporal analysis of precipitation concentration and dry spell in Qinghai, northwest China. Stoch Env Res Risk A 29(5):1403-1411

Kerr RA (2000) A North Atlantic climate pacemaker for the centuries. Science 288(5473):1984-1985

Kumar V, Jain SK, Singh Y (2010) Analysis of long-term rainfall trends in India. Hydrol Sci J J des Sci Hydrol 55(4):484-496

Mirza MQ, Warrick RA, Ericksen NJ, Kenny GJ (1998) Trends and persistence in precipitation in the Ganges, Brahmaputra and Meghna river basins. Hydrol Sci J 43(6):845-858

Schlesinger ME, Ramankutty N (1994) An oscillation in the global climate system of period 65-70 years. Nature 367(6465):723-726

Singh RB, Kumar S, Kumar A (2016) Climate change in Pindari region, Central Himalaya, India. In: Climate change, glacier response, and vegetation dynamics in the Himalaya. Springer International Publishing, pp 117-135

Sinha Ray KC, Srivastava AK (1999) Is there any change in extreme events like droughts and heavy rainfall. In: INTROPMET-97 (IIT New Delhi, 2-5 December 1997)

Vennila G (2007) Rainfall variation analysis of vattamalaikarai sub basin, Tamil Nadu. J Appl Hydrol 20(3):50

Willems P (2012) Impacts of climate change on rainfall extremes and urban drainage systems. Water Intelligence Online 11

Willems P (2013) Multidecadal oscillatory behaviour of rainfall extremes in Europe. Clim Change 120(4):931-944

Yue S, Hashino M (2003) Long term trends of annual and monthly precipitation in Japan. J Am Water Resour Assoc 39:587-596 